\title{
Journal of Infectious Diseases and Diagnosis
}

\section{Inhaled Micro- or Nanoparticles: Which are the Best for Intramacrophagic Antiinfectious Therapies?}

\section{Valentina lannuccelli ${ }^{*}$ and Eleonora Maretti}

Department of Life Sciences, University of Modena and Reggio Emilia, via Campi 103, Modena, Italy

*Corresponding author: Valentina lannuccelli, Department of Life Sciences, University of Modena and Reggio Emilia, via Campi 103 , Modena, Italy, Tel: +39059 2058559; E-mail: valentina.iannuccelli@unimore.it

Received date: October 22, 2015; Accepted date: October 30, 2015; Published date: November 07, 2015

Copyright: @ 2015 lannuccelli V, et al. This is an open-access article distributed under the terms of the Creative Commons Attribution License, which permits unrestricted use, distribution, and reproduction in any medium, provided the original author and source are credited.

\section{Intramacrophagic Anti-infectious therapies}

Nanotechnology is a fascinating world that has provided and still provides sensational developments in many fields such as in pharmaceutics for diagnosis or drug and gene delivery to cells, tissues or organs. With regard to the latter, cell uptake of nanostructures (generally $1-100 \mathrm{~nm}$ ) is usually much greater than that of microparticles in the range of 1-10 $\mu \mathrm{m}$. Although the term "nano" remains of high impact, not always the nanosize is preferable to a larger size. One of these cases is represented by the inhalation of drugs transported within particulate carrier in order to reach the Alveolar macrophages (AM) and eradicate surviving intracellular bacteria in pathologies such as tuberculosis, HIV, $S$. pneumoniae and $S$. aureus infections.

For an intra-macrophagic anti-infectious therapy by pulmonary administration, most antibiotics are poorly soluble in water and their aerosolization has to be produced by using drugs in their solid state administered by means of Dry powder inhaler (DPI) devices. In this regard, it is rare that untreated drugs have features suitable for both DPI performance and targeting to AM failing to both reach alveolar epithelium and penetrate AM effectively. Therefore, particle engineering techniques have been proposed for both drug alone (micronization, polymorphic transformations, controlled crystallization, intermolecular self-assembling, spray-drying producing irregular shaped particles) and drug/excipient blending (with lactose or mannitol) or carrier-based formulations (liposomes, polymeric/lipid microparticles, cyclodextrins).

Various inhaled particulate carriers containing therapeutic agents have been used to deliver drugs to the AM leading to intracellular concentrations of the antibiotic up to 20-fold enriched compared to the administration of free drug [1]. Particulate systems have also been engineered to facilitate uptake by macrophages or surface modified for receptor-mediated AM endocytosis [2].

Regarding particulate carrier-based formulations, among several other properties, particle size is crucial not only to guarantee effective dose emission by DPI, powder dispersion and deposition onto alveolar epithelium, but also effective endocytosis by AM that correlates with the efficacy of the loaded antimicrobial agents, i.e., the adequate local antibacterial concentration ( $>>$ MIC). The literature review shows several nanoparticle platforms for AM intracellular therapy.

Nevertheless, particle deposition onto the distal respiratory tract (breathability) is a prerogative of microsize particles in the aerodynamic size from 0.5 to $5 \mu \mathrm{m}$ (but also $0.5-3,0.5-2$, or 3-6 $\mu \mathrm{m}$ ranges are referred) while particles smaller than $0.5 \mu \mathrm{m}$ are mostly exhaled without deposition [3]. Contrary to this, particles larger than 2 or $5 \mu \mathrm{m}$, according to the data reported by the researchers, have a lower possibility of bypassing the upper airways. From the perspective of the AM endocytosis, the literature shows a wide view of dimensional conditions under which AM uptake would be subjected according to the size dictating endocytosis mechanism: phagocytosis (particularly $1-3 \mu \mathrm{m})$, macropinocytosis $(0.2-10 \mu \mathrm{m})$, or pinocytosis $(<0.2 \mu \mathrm{m})$.

It is essential to underline that cell-particle interactions are modulated also by other physico-chemical properties as well as cellspecific parameters such as macrophage type, i.e. the tissues where macrophage reside. For instance, some authors refer optimal sizes of the particles for the phagocytic uptake by AM in the range between 3 $\mu \mathrm{m}$ and $6 \mu \mathrm{m}$, but those by peritoneal macrophages and peripheral blood mononuclear cells from $0.3 \mu \mathrm{m}$ to $1.1 \mu \mathrm{m}$ [1]

However, the impact of particle size on both passive and active uptake is considered a key parameter with a tendency to assume and demonstrate that nanoparticles largely escape uptake by AM. Indeed, although endocytic mechanisms can involve nanoparticles, the actual amounts taken up should be assayed before a possible consideration. For example, $0.1 \%$ of the inhaled dose by macrophages within $24 \mathrm{~h}$ was found for inhaled $20 \mathrm{~nm}$ titanium dioxide particles. For comparison, macrophages uptake of 3 to $6 \mu \mathrm{m}$ particles was two orders of magnitude larger [4]. Contrary to this, microparticles of $1-3 \mu \mathrm{m}$ in diameter are far better and extensively taken up by AM and those of $1 \mu \mathrm{m}-10 \mu \mathrm{m}$ diameters are regarded to be the most favourable.

Thus, it seems reasonable sharing the opinion that the microparticles would be more effective than nanoparticles for the pulmonary treatment of intramacrophagic bacteria, especially in terms of breathability. For this reason, new technological approaches have led to the development of hybrid vectors in which nanoparticles are embedded in microparticulate shells so improving the aerodynamic properties of the native nanoparticles and, at the same time, reducing the possible nanoparticle harmful effects [5-7].

\section{References}

1. Hirota K, Hasegawa T, Nakajima T, Inagawa H, Kohchi C, et al. (2010) Delivery of rifampicin-PLGA microspheres into alveolar macrophages is promising for treatment of tuberculosis. J Control Release 142: 339-346.

2. Lee WH, Loo CY, Traini D, Young PM (2015) Nano- and micro-based inhaled drug delivery systems for targeting alveolar macrophages. Expert Opin Drug Deliv 12: 1009-1026.

3. Taylor K (2007) Pulmonary drug delivery. In: Aulton ME (ed.) Pharmaceutics: The Design and Manufacture of Medicines (3rdedn.), Edinburgh, Churchill Livingstone.

4. Geiser M, Kreyling WG (2010) Deposition and biokinetics of inhaled nanoparticles. Particle Fibre Toxicol 7: 2-17.

5. Duret C, Wauthoz N, Sebti T, Vanderbist F, Amighi K (2012) New inhalation-optimized itraconazole nanoparticle-based dry powders for the 
Citation: lannuccelli V, Maretti E (2015) Inhaled Micro- or Nanoparticles: Which are the Best for Intramacrophagic Antiinfectious Therapies?. J Infect Dis Diagn 1: e102.

Page 2 of 2

treatment of invasive pulmonary aspergillosis. Int J Nanomedicine 7: 5475-5489.

6. Fattal E, Grabowski N, Mura S, Vergnaud J, Tsapis N, et al. (2014) Lung toxicity of biodegradable nanoparticles. J Biomed Nanotechnol 10: 2852-2864
7. Tee N, Zhu Y, Mortimer GM, Martin DJ, Minchin RF (2015) Fluoromica nanoparticle cytotoxicity in macrophages decreases with size and extent of uptake. Int J Nanomedicine 10: 2363-2375. 